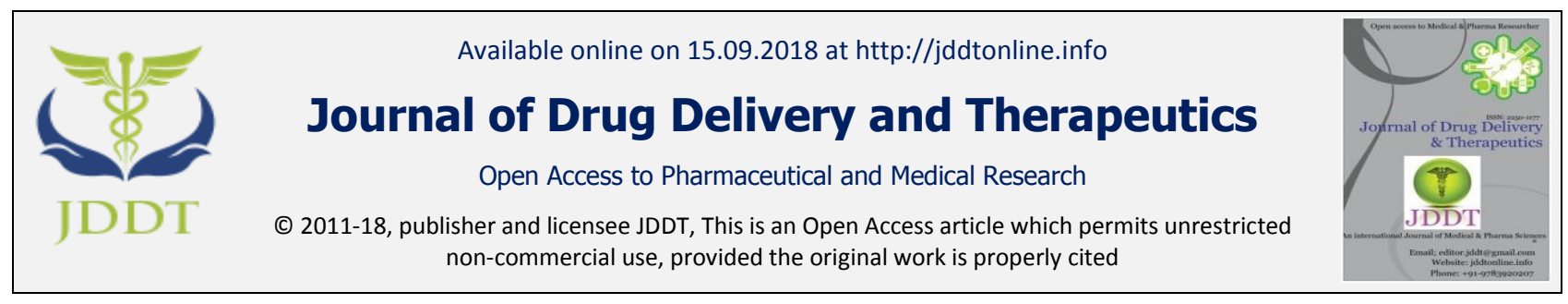

Open $\odot$ Access

Research Article

\title{
IN-VITRO FREE RADICAL SCAVENGING POTENTIAL OF FLAVONOIDS WITH SYNERGISTIC EFFECT OF THEIR COMBINATION
}

\author{
Rajesh Kumar*1, Shailendra Sharma ${ }^{2}$ \\ ${ }^{\mathbf{1}}$ Research Scholar, Jodhpur National University, Jodhpur, Rajasthan, India \\ ${ }^{2}$ Department of Pharmacy, Jai Narain Vyas University, Jodhpur 342011,Rajasthan,India.
}

\begin{abstract}
The present study was carried out to evaluate the possible synergistic interactions on antioxidant efficacy of some selected flavonoids in the present study, synergistic antioxidant effects of two flavonoids, rutin and quercetin, have been investigated by. DPPH, NO, free radical scavenging assays. Biological free radicals are highly unstable molecules that react with various organic substrates such as lipids, proteins, DNA causing cellular injury. At high concentrations, they generate oxidative stress, a damaging process that can damage all cell structures. At present, the research is focused on the use of antioxidants in preventing many diseases caused by the free radicals. The study was designed to evaluate in vitro antioxidant potential of quercetin, rutin, individually and synergistic antioxidant effects by using various in-vitro antioxidants assays i.e. DPPH, NO, assays. The scavenging effect of quercetin, rutin and standard on the DPPH radical was $83 \pm 2.71 \%, 79 \pm 1.51 \%$ and $86 \pm 1.04 \%$ at $60 \mu \mathrm{g} / \mathrm{ml}$. On NO Quercetin, rutin and standard exhibited $83 \pm 0.09 \%, 76 \pm 0.09 \%$ and $85 \pm 0.22 \%$. The scavenging activity increased in a dose dependent manner. The results indicate drugs shows significant free radical scavenging and their combination demonstrated considerable synergistic effect as compared to standard.
\end{abstract}

Keywords: Quercetin, Rutin, Free radical scavenging, Antioxidant

Article Info: Received 12 July, 2018; Review Completed 02 Aug 2018; Accepted 07 Aug 2018; Available online 15 Sep 2018

Cite this article as:

Kumar R, Sharma S, In-Vitro Free Radical Scavenging Potential of Flavonoids with Synergistic Effect of Their Combination, Journal of Drug Delivery and Therapeutics. 2018; 8(5):200-203

DOI: http://dx.doi.org/10.22270/jddt.v8i5.1851

*Address for Correspondence:

Rajesh Kumar, Research Scholar, Jodhpur National University, Jodhpur, Rajasthan, India

\section{INTRODUCTION}

Nature has been a source of medicinal agents form thousands of years and an remarkable number of modern drugs have been isolated from natural sources. Medicinal compounds from higher plants have continued to play a leading role in the maintenance of human health. ${ }^{1,2}$ Before the availability of synthetic drugs man was totally dependent on plant based drugs for their primary health care. ${ }^{3}$ Since ancient time, natural products obtained from plants have been used as a projecting source of prophylactic agents for the prevention and treatment of diseases in humans and animals. In recent years, the study on plant products has assumed a greater sense of urgency due to their dietary health benefits. peoples suffering from different diseases increases day by day due to increased pollution, harmful waste from industries, cigarette smoking, stress, exposure of body to UV radiation and electromagnetic radiations which causes production of free radicals. ${ }^{4}$ Biological free radicals are thus highly unstable molecules that have electrons available to react with various organic substrates such as lipids, proteins, DNA causing cellular injury. At high concentrations, they generate oxidative stress, a damaging process that can damage all cell structures. ${ }^{5-8}$ Oxidative stress plays a major role in the progress of chronic and degenerative ailments such as cancer, arthritis, aging, autoimmune disorders, cardiovascular and neurodegenerative diseases. Antioxidants are the compounds which scavenge the free-radicals and present the protection to 
living organisms from damage caused by uncontrolled production of these reactive oxygen species and subsequent lipid peroxidation, protein damage and DNA strand breaking. ${ }^{9}$ In recent years, the use of natural antioxidants present in food and other biological materials has attracted great interest due to their accepted safety, nutritional and therapeutic value. Many studies show that phytonutrients from fruits and vegetables may be valuable in defending the human body against damage caused by reactive oxygen and nitrogen species. Antioxidants derived from fruits, vegetables, spices and cereals are very effective and have reduced interference with the body's ability to use the free radicals. ${ }^{10}$

During the past decade, curiosity in polyphenols, including flavonoids has broadly increased due to the discovery of their various biological properties, mainly their antioxidant effects and their possible role in the prevention of several chronic diseases involving oxidative stress. Flavoinds is the most studied class of polyphenols. The polyphenolic nature of flavonoids is responsible for oxidation and the formation of stable radicals and it is presumed that flavonoids guard against free radical damage and act as antioxidants. Other biological properties include improved blood flow, the inhibition of cholesterol absorption and guard from damage by ultraviolet $B$ radiation. ${ }^{11}$ Quercetin (3,3', 4',5,7-pentahydroxyflavon) a well known plant pigment, belongs to the flavonols class of polyphenolic flavanoids. The majority of flavonoid intake includes upto $60-75 \%$ of quercetin and its glucosylated forms. ${ }^{12}$. Apples, berries, Brassica vegetables, capers, grapes, onions, shallots, tea, red wine, kale, and tomatoes, as well as many seeds, flowers and bark are the enriched dietary sources of quercetin. It also characterizes a main component of various medicinal plants including Ginkgo biloba, Hypericum perforatum (St. John'swort), Solanum Trilobatum and Sambucus Canadensis (elder) and many others. ${ }^{13}$.

Rutin, also known as quercetin-3-O-rutinoside (3,3',4',5,7-pentahydroxyflavone-3- Rhamnoglucoside), rutoside and sophorin, is a flavonol composed of the flavonoid quercetin and the disaccharide rutinose. The name 'rutin' came from a plant known as Ruta graveolens that also contains rutin ${ }^{14}$ (Shafi and Ikram, 1982). Initially, rutin was called vitamin-P but it is not actually a vitamin. Dietary sources containing high concentration of rutin include teas, asparagus, rhubarb, peels and rinds of citrus fruits, apple, berries such as mulberry, ash tree fruits, aronia berries and cranberries ${ }^{15}$ (Jasuja et al., 2012). Buckwheat seeds, flowers and leaves of Rue, Pansy and Rose are also identified as richest sources of rutin ${ }^{16}$ (Sofic et al., 2010). It is also used as a coloring agent, food additive and used in $\operatorname{cosmetics}^{17}$ (Fathiazad et al., 2006). The present study was conducted to explore the possibility of an in vitro synergistic effect of quercetin and rutin combination as compared with each drug alone.

\section{MATERIAL AND METHODS}

Chemical and reagents
Quercetin, rutin, 2,2-diphenyl-1-picrylhydrazyl(DPPH), methanol, sodium nitroprusside, naphthyl ethylenediamine dihydrochloride, sulphanilamide, phosphoric acid, were obtained from SD fine chemicals, Himedia or Sigma loba chemicals. All other reagents used were of analytical grade.

\section{DPPH Radical Scavenging Activity ${ }^{18}$}

The antioxidant activity of the quercetin, rutin was determined in terms of hydrogen donating or radical scavenging ability, using the stable radical DPPH, according to method of Dnyaneshwar M. Nagmoti, et al. A methanol solution of the sample at various concentrations $(30-60 \mu \mathrm{g} / \mathrm{ml})$ was added to $0.5 \mathrm{ml}$ of 0.1 $\mathrm{mM}$ methanolic solution of DPPH and allowed to stand for $30 \mathrm{~min}$ at $25^{\circ} \mathrm{C}$. The absorbance of the sample was measured at $517 \mathrm{~nm}$. A $0.1 \mathrm{mM}$ solution of DPPH in methanol was used as control, whereas ascorbic acid was used as reference standard. All tests were performed in triplicate. Radical scavenging activity is expressed as the inhibition percentage of free radical by the sample and standard was calculated using the formula

$$
\% \text { inhibition }=\frac{[\text { (Abs }(\text { control })-\text { Abs }(\text { test })]}{(\text { Abs }(\text { control })} \times 100
$$

\section{Nitric oxide (NO•) scavenging activity ${ }^{19}$}

Nitric oxide scavenging activity quercetin and rutin was determined in terms of $\mathrm{NO} \cdot$ generated from sodium nitroprusside in aqueous solution at physiological $\mathrm{pH}$ interacts with oxygen to produce nitrite ions, which were measured by the Griess reaction. ${ }^{19}$ One milliliter of sodium nitroprusside $(10 \mathrm{mM})$ in phosphate-buffered saline ( $\mathrm{pH}$ 7.4) was mixed with $1 \mathrm{ml}$ of test solution at various concentrations $(30-60 \mu \mathrm{g} / \mathrm{ml})$ dissolved in methanol and a control without a test compound, but with an equivalent amount of methanol. The mixture was incubated at $25^{\circ} \mathrm{C}$ for $30 \mathrm{~min}$. After $30 \mathrm{~min}, 1 \mathrm{ml}$ of the incubated solution was withdrawn and mixed with 1 $\mathrm{ml}$ of Griess reagent (1\% sulphanilamide, 2\% phosphoric acid and $0.1 \%$ naphthyl ethylenediamine dihydrochloride). The absorbance of the pink chromophore formed during the diazotization of the nitrite with sulphanilamide and the subsequent coupling with naphthyl ethylenediamine dihydrochloride was measured at $546 \mathrm{~nm}$. All the tests were performed in triplicate. Percentage inhibition was calculated using Equation

$$
\% \text { inhibition }=\frac{[(\text { Abs }(\text { control })-\text { Abs }(\text { test })]}{(\text { Abs }(\text { control })} \times 100
$$

\section{RESULTS AND DISCUSSION}

\section{DPPH radical scavenging activity}

This method has been widely used to determine the free radical scavenging activity of antioxidants. The method is based on the reduction of an alcoholic DPPH solution in the presence of a hydrogen donating antioxidant. When an odd electron of DPPH radical paired with hydrogen, it reduces to DPPH-H which leads to change in colour depending upon the number of electrons taken up. Reduction of the DPPH radicals can be observed by the decrease in absorbance at $517 \mathrm{~nm} .{ }^{18}$. Prasad et al. ${ }^{19}$ 
reported that phenolics and flavonoids reduce the DPPH radicals by their hydrogen donating ability. ${ }^{20}$

The effect of quercetin and rutin on 1, 1-Diphenyl-2Picrylhydrazyl (DPPH) radical scavenging activity is shown in Table 1 and Figure 1. The quercetin and rutin showed the DPPH radical scavenging activity in a concentration dependent manner. Both the drugs under test show significant effect when compared to standard ascorbic acid. The quercetin and rutin showed IC50 value of $28.40 \mu \mathrm{g} / \mathrm{ml}$ and $33.34 \mu \mathrm{g} / \mathrm{ml}$. This shows that quercetin has more scavenging power than rutin.

\section{Nitric oxide scavenging activity}

Nitric oxide (NO) is a free radical involved in the regulation of various physiological processes. However, excess production of $\mathrm{NO}$ is associated with several diseases. Nitric oxide is a very unstable species under aerobic conditions. It reacts with $\mathrm{O}_{2}$ to produce stable product nitrate and nitrite. The procedure is based on the principle that, sodium nitroprusside in aqueous solution at physiological $\mathrm{pH}$ spontaneously generates nitric oxide which interacts with oxygen to produce nitrite ions that can be estimated using Griess reagent. ${ }^{21}$

Suppression of $\mathrm{NO} \cdot$ release may be attributed to a direct NO- scavenging effect of the extracts decreased the amount of nitrite generated from the decomposition of sodium nitroprusside in vitro as shown in Table 2 and Figure 2. The results show that scavenging activity in a concentration dependent $(25-100 \mu \mathrm{g} / \mathrm{ml})$ The quercetin and rutin showed IC50 value of $42.05 \mu \mathrm{g} / \mathrm{ml}$ and $44.18 \mu \mathrm{g} / \mathrm{ml}$.

Table 1:-DPPH radical scavenging activities of quercetin, rutin and standards. Each value is expressed as a mean \pm S.E.M $(n=3)$.

\begin{tabular}{|c|c|c|c|c|}
\hline \multirow{2}{*}{ S.No. } & \multirow{2}{*}{ Concentration } & \multicolumn{3}{|c|}{ Precentage scavenging activity } \\
\cline { 3 - 5 } & 30 & Quercetin (test) & Rutin(test) & Ascorbic acid (std.) \\
\hline 1 & 40 & $50 \pm 1.83$ & $44 \pm 0.91$ & $53 \pm 1.04$ \\
\hline 2 & 50 & $62 \pm 1.04$ & $59 \pm 1.80$ & $66 \pm 0.60$ \\
\hline 3 & 60 & $79 \pm 2.40$ & $74 \pm 1.20$ & $82 \pm 1.25$ \\
\hline 4 & $83 \pm 2.71$ & $79 \pm 1.51$ & $86 \pm 1.04$ \\
\hline
\end{tabular}

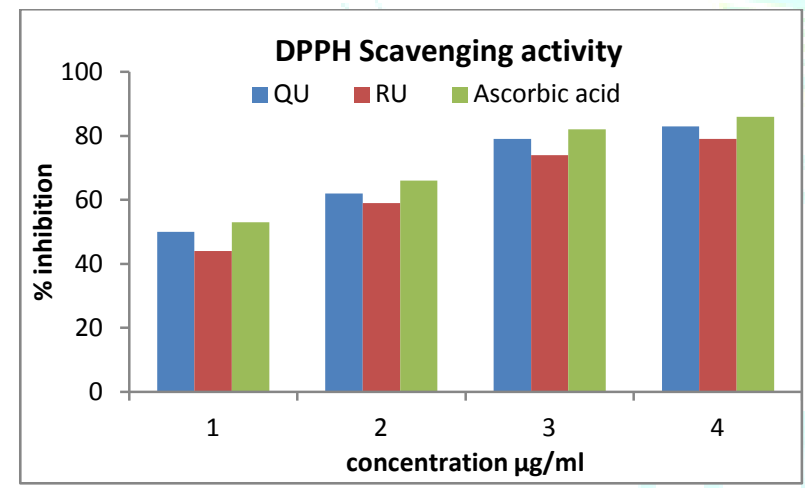

Figure 1: DPPH radical scavenges activities of quercetin, rutin and standards. Each value is expressed as a mean \pm S.E.M $(n=3)$.

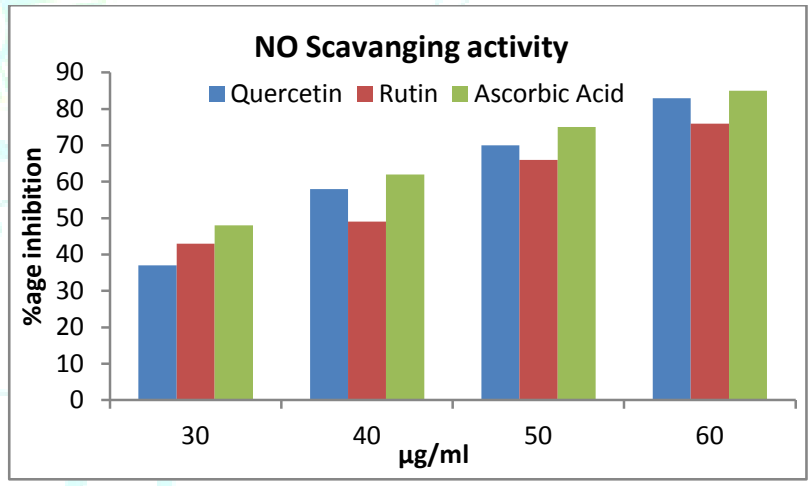

Figure 2: NO radical scavenging activities of quercetin and control standards. Each value is expressed as a mean \pm S.E.M $(n=3)$.

Table 2: NO radical scavenging activities of quercetin, rutin and standards. Each value is expressed as a mean \pm S.E.M $(n=3)$.

\begin{tabular}{|c|c|c|c|c|}
\hline & & \multicolumn{3}{|c|}{ Percentage scavenging activity } \\
\cline { 3 - 5 } S.No. & Concentration & Quercetin (test) & Rutin (test) & Ascorbic acid (std.) \\
\hline 1 & 25 & $37 \pm 0.16$ & $43 \pm 0.24$ & $48 \pm 0.27$ \\
\hline 2 & 50 & $58 \pm 0.09$ & $49 \pm 0.19$ & $62 \pm 0.27$ \\
\hline 3 & 75 & $70 \pm 010$ & $66 \pm 0.18$ & $75 \pm 0.13$ \\
\hline 4 & 100 & $83 \pm 0.09$ & $76 \pm 0.09$ & $85 \pm 0.55$ \\
\hline
\end{tabular}

Table 3: DPPH radical scavenging activities of quercetin+ rutin and standards. Each value is expressed as a mean \pm S.E.M $(n=3)$.

\begin{tabular}{|c|c|c|c|c|}
\hline & & & \multicolumn{2}{|c|}{ Percentage scavenging activity } \\
\cline { 4 - 5 } S.No. & Concentration & Absorbance & Qu+Ru (test) & Ascorbic acid (std.) \\
\hline 1 & 30 & 0.47 & $51 \pm 0.158$ & $53 \pm 1.040$ \\
\hline 2 & 40 & 0.35 & $63 \pm 0.067$ & $66 \pm 0.636$ \\
\hline 3 & 50 & 0.22 & $77 \pm 0.121$ & $82 \pm 1.252$ \\
\hline 4 & 60 & 0.16 & $84 \pm 0.227$ & $86 \pm 1.043$ \\
\hline
\end{tabular}


Table 4: NO radical scavenging activities of quercetin and control standards. Each value is expressed as a mean \pm S.E.M $(n=3)$.

\begin{tabular}{|c|c|c|c|c|}
\hline & & \multirow{2}{*}{} & \multicolumn{2}{|c|}{ Percentage scavenging activity } \\
\cline { 4 - 5 } S.No. & Concentration & Absorbance & Qu+Ru (test) & Ascorbic acid (std.) \\
\hline 1 & 25 & 0.51 & $45 \pm 1.772$ & $48 \pm 0.237$ \\
\hline 2 & 50 & 0.45 & $60 \pm 0.293$ & $62 \pm 0.270$ \\
\hline 3 & 75 & 0.34 & $74 \pm 0.224$ & $75 \pm 0.103$ \\
\hline 4 & 100 & 0.17 & $78 \pm 0.084$ & $85 \pm 0.220$ \\
\hline
\end{tabular}

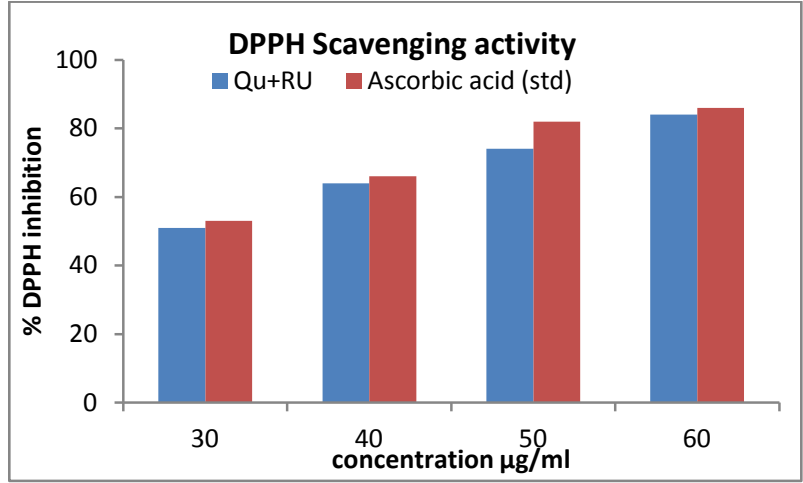

Figure 3: DPPH radical scavenging activities of quercetin, rutin and standards. Each value is expressed as a mean \pm S.E.M $(n=3)$.

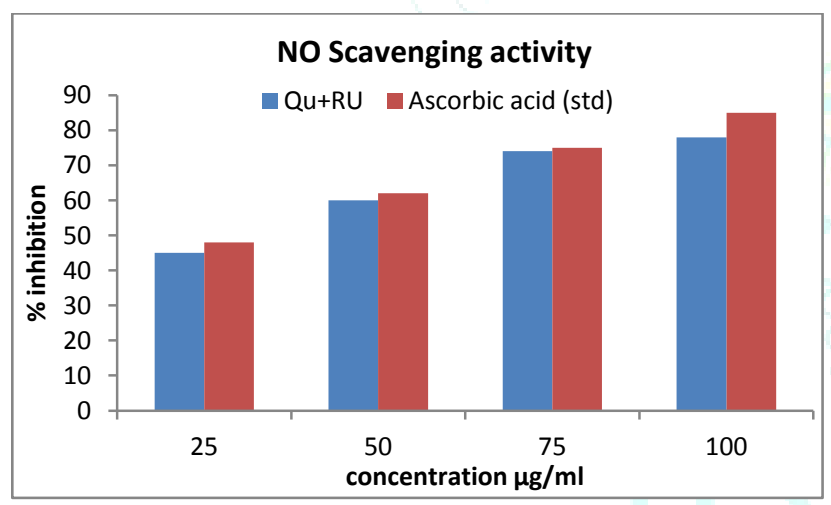

Figure 4: NO radical scavenging activities of quercetin and control standards. Each value is expressed as a mean \pm S.E.M $(n=3)$.

\section{CONCLUSION}

From the result obtained in this study, it is concluded that both quercetin and rutin exhibit antioxidant activity. These in vitro assays indicate that quercetin is stronger anti oxidant than rutin. The data shown in figure 4 is due to synergistic effect of both above mentioned compounds. The present study indicate that quercetin and rutin have strong anti oxidant potential and their combination shows additive effect can be used as promising natural source of anti oxidants for application in nutritional and pharmaceutical field, in prevention of diseases caused by free radicals.

\section{REFERENCES}

1. Crag G.; Newman, D. J. Medicines for the millennia. Ann. NY Acad. Sci. 2001; 953:3-25.

2. Farombi, E.O. African indigenous plants with chemotherapeutic potentials and biotechnological approach to the production of bioactive prophylactic agents. Afr. J. Biotech. 2003; 662-671.

3. Singh A, Malhotra S, Subban R. Anti-inflammatory and analgesic agents from Indian medicinal plants. Int. J. Integr. Biol. 2008; 3:57.

4. Halliwell B, Gutteridge J.M.C. Free radicals in biology and medicine. Clarendon Press: Oxford, UK, 2007

5. Willcox J.K, Ash S.L., Catignani G.L. Antioxidants and prevention of chronic disease. Crit. Rev. Food Sci. Nutr. 2004; 44:275-95.

6. Genestra M. Oxyl radicals, redox-sensitive signaling cascades and antioxidants. Cellsig. 2007; 19:1807-1819.

7. Halliwell B. Biochemistry of oxidative stress. Biochem. Soc. Trans. 2007; 35:1147-1150.

8. Young I, Woodside J. Antioxidants in health and disease. J. Clin. Pathol. 2001; 54:176-186.

9. Iris F.F. Evolution of dietary antioxidants. Comparative Biochemistry and Physiology 2003; 136:113-126.

10. Wolfe K, Xianzhong W.U., Liu R.H. Antioxidant activity of apple peels. J. Agricul. Food Chem. 2003; 51:609-614.

11. Westhuizen JHV, Sisa MB, Ferreira SLD. Photochemistry of Flavonoids. Molecules. 2010; 15:5196-5245.

12. Bouktaib Metal. Regio- and stereoselective synthesis of the major metabolite of quercetin, quercetin-3-O-b-Dglucuronide. Tetrahedron Letters, 2002; 43:6263-6266.

13. Kleemann R, Verschuren L, Morrison M, Zadelaar S, Van Erk MJ, Wielinga PY and Kooistra, T. Anti-inflammatory, anti-proliferative and anti-atherosclerotic effects of quercetin in human in vitro and in vivo models. Atherosclerosis. 2011; 218:44-52.

14. Shafi N, Ikram M. Quantitative survey of rutin containing plants. Part 1. Pharmaceutical Biol. 1982; 20:183-186.

15. Jasuja R, Passam FH, Kennedy DR, Kim SH, Hessem LV, Lin L, Bowley SR, Joshi SS, Dilks JR, Furie B, Furie BC. and Flaumenhaft R. Protein disulfide isomerase inhibi-tors constitute a new class of antithrombotic agents. Journal of Clinical Investigation. 2012; 122(6):2104-2113.

16. Sofic E, Copra-Janicijevic A, Salihovic M, Tahirovic I and Kroyer G. Screening of medicinal plants extracts for quercetin-3-rutinoside (rutin) in Bosnia and Herzegovina. Medicinal plants. 2010; 2(2):97-102.

17. Fathiazad F, Delazar A, Amiri R and Sarker SD. Extraction of flavonoids and quantification of rutin from waste tobacco leaves. IJPR. 2006; 5:222-227.

18. Dnyaneshwar M, Nagmoti et al.: Antioxidant activity and free radical-scavenging potential of Pithecellobium dulce Free Radicals and Antioxidants 2012; 2(2):39-40

19. Ganapaty S, Chandrashekhar VM, Chitme HR, Lakashami NM. Free radical scavenging activity of gossypin and nevadensin: An in vitroevaluation. Indian J Pharmacol. 2007; 39(6):281-3.

20. Prasad KN, Divakar S, Shivamurthy GR, Aradhya SM, "Isolation of a free radical-scavenging antioxidant from water spinach (Ipomoea aquatica Forsk)," Journal of the Science of Food and Agriculture, 2005; 85(9):1461-1468.

21. Shirwaikar Prabhu KS, I. Punitha ISR, "In vitro antioxidant studies of Sphaeranthus indicus (Linn)," Indian Journal of Experimental Biology, 2006; 44(12):993-99. 